\title{
Recursos digitais na formação de professores de Ciências: alargamento de sentidos
}

\section{Digital resources in the training of science teacher: enlargement sense}

\author{
Alessandra Rodrigues, Mikael Frank Rezende Junior, Rita de Cássia M. T. Stano \\ Universidade Federal de Itajubá, Brasil
}

\begin{abstract}
Resumo
Este trabalho investiga os efeitos da utilização de recursos digitais no desenvolvimento das atividades de uma disciplina do Programa de Mestrado Profissional em Ensino de Ciências de uma universidade pública brasileira. Foram foco do estudo as produções acadêmicas de 7 mestrandos, constitutivas de um portifólio digital cujo suporte foi um blog. As análises indicam: a) um processo gradativo de apropriação tecnológica; b) intensificação das interações para além da sala de aula; c) alargamento da proposta inicial da disciplina. Destaca-se, assim, que as ferramentas digitais constituem-se valioso recurso para a formação de professores e, nesse contexto, podem instigar o uso pedagógico das tecnologias no ensino de ciências. Palavras-chave: ensino de ciências, formação de professores, TIC, currículo.
\end{abstract}

\section{Abstract}

This work is the result of a research with students of a master's program in Science Teaching offered by a Brazilian public university within a research line named "Information and Communication Technology in Science Education". We have studied the academic production of two classes, totaling 7 graduate students (teachers working at public and private schools either in basic and higher education). Such production aimed at establishing a digital portfolio, using a blog as a platform. The analysis show: a) a gradual process of technological appropriation; b) unfolding the technology appropriation and application of the resources in the teaching practice of the graduate students; c) intensification of the interaction beyond the classroom; d) expansion of the initial proposal. Thus it is emphasized that digital tools constitute a valuable resource for teacher training and can instigate the pedagogical use of technologies in Science Education.

Keywords: science education, teacher training, ICT, curriculum.

\section{Introdução}

O ensino de ciências no Brasil historicamente apresenta um cenário tanto de carência de quantitativo docente nas áreas de Biologia, Física, Química e Matemática quanto de necessidade de formação continuada dos professores das redes pública e privada; e, ainda que nos últimos anos a oferta de vagas voltadas à formação inicial de professores de ciências no sistema de ensino brasileiro tenha sido ampliada, Araujo e Vianna (2011) indicam que medidas complementares à ampliação de vagas são necessárias para a solução dessa carência quantitativa.
Tal contexto tem sido foco de atenção das Universidades brasileiras, no sentido de oferecer formação inicial e continuada de qualidade com vistas à melhoria da prática docente nas áreas específicas e ao uso de recursos didático-pedagógicos condizentes com a realidade atual. É nesse contexto que se insere este trabalho, resultado de investigação realizada no período que compreendeu o binênio 2013/2014 junto a discentes do Programa de Pós-Graduação em Ensino de Ciências Mestrado Profissional, de uma universidade pública brasileira, dentro da linha de pesquisa "Tecnologias de Informação e Comunicação no Ensino de Ciências”. Objetivou-se investigar os efeitos da utilização de recursos digitais no desenvolvimento das atividades da disciplina de "Tendências Contemporâneas de Currículo”.

\section{Método}

Este estudo tem origem na disciplina "Tendências Contemporâneas de Currículo” em um mestrado profissional de ensino de ciências. Esta disciplina tem carga horária de 45 horas semestrais, é presencial e disposta no rol de disciplinas optativas para os mestrandos. Os temas propostos no programa da disciplina incluem as concepções, paradigmas e trajetórias do currículo como conceito e área de investigação; e a relação das Ciências com a prática curricular na educação brasileira.

No contexto de desenvolvimento da disciplina nas turmas de 2013 e 2014, propôs-se como atividade aos mestrandos a criação de um blog individual, onde esses estudantes deveriam postar reflexões, resenhas, resumos e comentários sobre os temas e textos estudados. A observação do processo de construção dos blogs levou à seguinte indagação: que efeitos a utilização desse recurso digital estaria gerando na construção da disciplina e na aprendizagem dos mestrandos?

Finalizada a disciplina nas duas turmas citadas, foram produzidos 13 blogs pelos mestrandos. Uma análise prévia foi realizada a fim de mapear respostas à indagação feita, bem como as possíveis categorias de análise deste estudo. Dentre os blogs, 7 traziam uma postagem com um texto reflexivo e autoavaliativo sobre a experiência desenvolvida na disciplina, e por essa razão tais blogs foram escolhidos para compor o corpus deste estudo. 


\section{Participantes}

Os sujeitos que são autores dos blogs a serem analisados têm perfis semelhantes de formação e atuação profissional; além de serem todos mestrandos em Ensino de Ciências. Dos sete sujeitos deste estudo, dois são homens e 5 mulheres. A formação inicial apresenta-se da seguinte forma: quatro sujeitos são graduados em Física; um em Matemática; um em Ciências Biológicas; um em Enfermagem. Seis dos sujeitos têm experiência na área da educação, atuando como professores em diferentes níveis de ensino: um sujeito já atuou como docente no Ensino Superior; três na Educação Básica; um no Ensino Técnico; dois atuam como tutores da Educação a Distância (conciliando com outras atividades profissionais e docência na Educação Básica).

\section{Procedimentos de Análise de Dados}

Os dados foram analisados qualitativamente. As categorias de análise, construídas a partir da leitura prévia dos blogs são: apropriação tecnológica; currículo; e transformação/aprendizagens. A primeira categoria ocupa-se de identificar indícios de apropriação da tecnologia pelos sujeitos. Nosso interesse neste texto não é aprofundar o conceito de apropriação, mas tomamos como referência para as análises a ideia de Buzato (2009, p. 08), segundo a qual, "ao participarem de atividades em que a tecnologia é relevante, as pessoas adaptam e modificam o seu significado por meio da interação social (negociação de sentidos) em torno dos usos da tecnologia. Apropriação, portanto, passa de uma precondição a um sinônimo de transformação”.

A categoria “currículo” está associada ao caminho formativo percorrido pelos sujeitos, e documentado de alguma maneira nos blogs, buscando compreender os impactos do uso desse recurso no desenvolvimento da disciplina. Importante salientar que nossa concepção de currículo associa-se às proposições de Gimeno Sacristán (2000; 2013), Almeida e Valente (2011), Apple (2006), Arroyo (2013), Lopes e Macedo (2011) entre outros autores, cuja compreensão situa o currículo como uma construção histórica, social, política e ideológica atravessada por relações de poder e sempre multifacetada. Assim, entendemos que o currículo "é reconhecido no seu processo de desenvolvimento" (GIMENO SACRISTÁN, 2013, p. 25).

A terceira categoria "transformações e aprendizagens" volta-se aos indicativos, dados pelos mestrandos nos blogs, de mudanças desencadeadas pela disciplina.

Para auxiliar as análises foi utilizado o NVivo, um software de auxílio à pesquisa qualitativa e mista que permite reunir, organizar e analisar conteúdos de entrevistas, discussões em grupo, questionários, audios, mídias sociais e páginas web. De acordo com Lage (2011), o NVivo é um dos softwares mais utilizados no ambiente acadêmico brasileiro e vem dando suporte a pesquisas em grandes universidades do Brasil. Os blogs foram capturados da internet e inseridos no software. Posteriormente, foram selecionados os extratos textuais associados a cada categoria de análise, cada uma representada no NVivo por um “nó”. Os blogs analisados tiveram uma média de 16 postagens, totalizando 110 posts, que constituíram nosso corpus de análise. Além do conteúdo textual das postagens, as análises consideraram a forma de utilização do blog e a inserção de outros elementos, além dos textos escritos, especialmente na categoria "apropriação tecnológica”.

Cabe lembrar que, para preservar a identidade dos sujeitos, eles serão identificados por P1, P2, P3.... Pn.

\section{Resultados}

Relativamente ao aspecto geral dos blogs analisados, salientamos que todos apresentaram interfaces diferentes entre si, geralmente associadas à características pessoais ou profissionais dos sujeitos. P1, cuja formação é em Ciências Biológicas, construiu seu blog tendo como pano de fundo um barco e as águas em que ele navegava. P2, cuja formação é Matemática, utilizou como fundo imagens de fórmulas. P5, graduada em Enferrnagem, escolheu a imagen de um livro antigo entreaberto. P3, P4, P6 e P7 escolheram temas que não estão associados à aprendizagem ou formação/atuação profissional; mas imagens de uma estrada (P7) e desenhos abstratos cujas cores remetem à jovialidade dos sujeitos ou ao seu perfil mais sóbrio.

Relativamente à categoria “apropriação tecnológica” percebeu-se na construção dos blogs de P2, P3, P4 e P6 a inserção de vídeos com a finalidade de enriquecer ou ilustrar as reflexões, comentários e discussões de algumas postagens. O excerto de P6 é ilustrativo dessas situações: "Nessa postagem trago uma breve reflexão sobre a temática que esteve presente em nossa última aula [...] e a relaciono com um vídeo. Antes da reflexão vamos ao vídeo".

Outro aspecto a ser mencionado nesta categoria de análise é a inclusão, nos blogs de P1, P2 e P4 de imagens associadas ao texto escrito, ilustrando-o e complementando seu sentido. Além disso, P1 e P5 incluíram fotografias da turma de mestrandos em seus textos finais de autoavaliação.

Cabe ainda apontar a inserção, por P2, P4 e P6, de charges e postagens cujo conteúdo não estava diretamente relacionado aos textos estudados na disciplina ou às atividades solicitadas pela docente. Exemplar dessa situação é a postagem de P2, a seguir: “Boa noite!!! Seguindo a onda dos protestos, eu estava passeando pelo Facebook do meu pai e encontrei essa imagem muito bacana:"

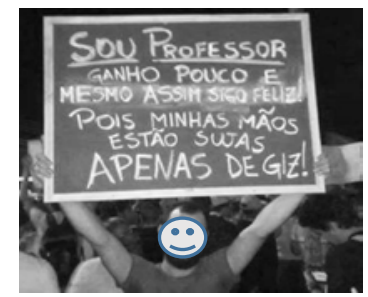

Créditos para: https://www.facebook.com/HistoricasImagens

Outra postagem representativa desse aspecto foi feita por P6: “Olá, boa tarde colegas! A postagem de hoje é apenas uma pequena prestação de serviços, trata-se de 
um breve artigo, muito interessante por sinal, que fala sobre coisas que não devemos fazer em nossa dissertação. =D”.

Na categoria “currículo” são relevantes para este estudo as postagens a seguir:

"[...] durante o semestre fui me modificando [...] exemplos vividos pelos colegas e compartilhados em sala que colaboram com as discussões" (P2 - grifos nossos).

"Minha visão foi modificando através de muitos textos e principalmente muitas discussões" (P3 - grifos nossos).

"Poder trocar ideias e compartilhar nossas reflexões através do blog foi uma ótima experiência” (P4 - grifo nosso).

"A disciplina foi marcada por lições de fazer, desfazer e refazer" (P5 - grifo nosso).

"Com o decorrer da disciplina, uma gradativa desconstrução foi ocorrendo. [...] A disciplina foi muito dinâmica e possibilitou a participação de todos nas discussões” (P7 - grifos nossos).

$\mathrm{Na}$ categoria dedicada às transformações e aprendizagens descritas pelos sujeitos ao final do processo desencadeado pela disciplina, figuram como resultados os seguintes extratos, divididos em dois blocos para facilitar a discussão posterior.

Bloco 1:

“[...] quero aqui declarar as mudanças que me atingiram de forma profunda e que provocaram grandes transformações. Vejo que após esta disciplina encontrei uma nova forma de enxergar o professor, nas muitas formas de ser, de fazer e de aprender". (P1)

"Essas discussões, sempre enriquecedoras, fizeram-me refletir e repensar sobre vários aspectos da minha vida profissional e pessoal”. (P2)

"aprendi que meus erros eram tão importantes quanto meus acertos, afinal não há aprendizado na vida que não passe pela experiência dos erros”. (P3)

"Mudar concepções e regras em busca da qualidade do ensino de minhas aulas, de minhas avaliações, de meu comportamento. [...] aprendi principalmente que sou capaz de alcançar voos mais altos, de criar, de recriar e buscar sempre o melhor para aquilo que desejei ser... 'professora',. (P5)

"a práxis deve estar presente em todas as nossas atividades”. (P6)

Bloco 2:

"Aprendi e redescobri outras histórias, experiências, críticas e além de tudo: sabedoria”. (P1)

"Aprendi a respeitar a sabedoria e as experiências dos educadores mais velhos, sendo estes formadores tradicionais ou contemporâneos”. (P5)

\section{Discussão}

A discussão dos dados apresentados seguirá as categorias de análise, mas inicialmente pontuamos a personificação dos blogs feita pelos mestrandos tanto como uma forma de posicionamento dos sujeitos diante da alteridade quanto como uma forma de inserção da subjetividade no contexto fortemente objetivo da formação em nível de pós-graduação. Entendemos que a utilização desse recurso digital favoreceu o diálogo subjetividade-objetividade, uma vez que “O blog é concebido como um espaço em que o escrevente pode expressar o que quiser na atividade da (sua) escrita, com a escolha de imagens e de sons que compõem o todo do texto" (KOMESU, 2010, p. 139). Ainda que o escopo do blog fossem as postagens de conteúdo acadêmico-curricular, os sujeitos o organizaram de forma que alguns aspectos de sua identidade estivessem constantemente presentes por meio das imagens de fundo das páginas virtuais.

Também podemos interpretar essa escolha dos sujeitos como um indício de que os blogs, pelas próprias características desse suporte, já convidem à uma postura mais autoral, instigando os sujeitos a se exporem no texto e relativamente ao conteúdo curricular que devem discutir. A condição autoral solicita o mostrar-se, o dar-se a ver (FOUCAULT, 1992) em busca do reconhecimento de si e do outro num movimento que exige a presença e o posicionamento do autor (RODRIGUES, 2011).

Os dados da primeira categoria indicam um processo inicial de apropriação da tecnologia por meio da atribuição de sentidos aos recursos tecnológicos, seguindo o entendimento de Buzato (2009) sobre o conceito de apropriação. As postagens de vídeos e imagens para complementar e/ou ilustrar os textos escritos mostra que os sujeitos, ainda que não tivessem sido instigados a isso, compreendem que o suporte tecnológico demanda uma escrita associada a outros elementos. Trata-se de um movimento de adaptação e adequação à linguagem multimidiática e multissemiótica que está atrelada às tecnologias digitais de informação e comunicação, mas também de um movimento de transformação (BUZATO, 2009) do uso habitual do texto escrito pelos sujeitos.

Pela inserção desses elementos em suas construções textuais, os sujeitos realizam pelo menos duas ações: a de utilizar outras linguagens e mídias na composição discursiva; e a de incluir elementos que remetem à sua cultura, identidade, preferências estéticas etc. Em outras palavras, essas ações mostram a apropriação e a significação da tecnologia em direção a multiletramentos. Rojo (2013) nos ajuda a compreender esses movimentos ao afirmar que os multiletramentos implicam tanto a multiplicidade de linguagens quanto a pluralidade e a diversidade cultural trazidas pelos sujeitos para os contextos de comunicação mediados pelas tecnologias.

A atribuição de sentidos também pode ser percebida pela inserção de fotografias do grupo de mestrandos no texto final de autoavaliação. Como apontam Santaella e Nöth (2012, p. 204), a fotografia, como "emanação da realidade passada” cuja mensagem é “esta é a maneira como tem sido", funciona como uma afirmação da existência do objeto representado por ela. Nesse caso, a imagem do grupo funciona como uma comprovação das relações estabelecidas na disciplina e descritas no texto 
escrito. Ou seja, os sujeitos materializam, pela fotografia digital inserida no blog, o processo de construção do conhecimento vivenciado durante o período letivo por meio da interação social em torno dos usos da tecnologia, como aponta Buzato (2009).

Por fim, a inclusão no blog de charges, textos e imagens cujo conteúdo não estava vinculado diretamente ao conteúdo curricular prescrito da disciplina nos indica outro movimento de atribuição de sentidos para o uso da tecnologia que nos parece ser o mais interessante porque se desdobra em vários aspectos: a) remete ao estabelecimento, pelos sujeitos, de um diálogo entre a educação formal e a vida, entre o que acontece dentro dos muros da Universidade e o que é desencadeado no contexto externo (como na postagem de P2, em que o conteúdo trata das manifestações públicas ocorridas no Brasil em 2014); b) mostra que os sujeitos passam a ver o blog criado para postagem de atividades curriculares como um espaço propício para o compartilhamento de outras demandas (como exemplifica a postagem de P6 com dicas para a escrita da dissertação) e; c) indica uma ampliação do objetivo inicial do blog e da própria utilização desse recurso tecnológico na disciplina.

Esses aspectos nos parecem indicar, além da apropriação tecnológica por meio da ressignificação da tecnologia, elementos indiciários de uma integração das TIC ao currículo. A esse respeito, Almeida e Valente (2011, p. 31) defendem a importância de utilizarmos a tecnologia para "potencializar práticas pedagógicas que propiciem um currículo voltado ao desenvolvimento da autonomia do aluno na busca e na geração de informações significativas para compreender o mundo e atuar na sua reconstrução”.

Nossa próxima categoria de análise volta-se ao currículo desenvolvido no decorrer da disciplina segundo as postagens dos mestrandos nos blogs. Notamos, pelos excertos dos textos de P2, P3, P4, P5 e P7 a percepção do desenvolvimento processual da disciplina bem como referências ao próprio desenvolvimento gradual dos sujeitos: "fui me modificando" (P2); "minha visão foi modificando" (P3); "lições de fazer, desfazer e refazer" (P5); “uma gradativa desconstrução foi ocorrendo” (P7).

Pelos trechos destacados, percebemos uma construção curricular processual que provocou movimentações nos sujeitos da aprendizagem levando-os a ressignificar seu próprio processo de aprender como um vai e vem que permite erros, desconstruções, reflexões e reconstruções; um currículo entendido como "prática de significação, como criação ou enunciação de sentidos” (LOPES; MACEDO, 2011, p. 42).

Também por isso, um currículo que se estrutura pelo e no coletivo, no diálogo: "exemplos vividos pelos colegas e compartilhados colaboram com as discussões" (P2); "muitos textos e principalmente muitas discussões" (P3); "compartilhar nossas reflexões através do blog foi uma ótima experiência" (P4); "A disciplina foi muito dinâmica e possibilitou a participação de todos nas discussões" (P7).
A ampliação das reflexões e discussões empreendidas no contexto presencial se deu por meio da utilização dos blogs. Esses funcionaram, assim, como contextos de intercâmbio para a aprendizagem, nos quais, como refere Lévy (1992, p. 28), desenvolveu-se o jogo da comunicação - que "consiste em, por meio de mensagens, precisar, ajustar, transformar o contexto partilhado pelos parceiros”.

Na categoria dedicada à apreender as transformações e aprendizagens descritas pelos sujeitos como decorrentes da experiência vivenciada na disciplina, entendemos que o primeiro bloco de excertos aponta para reflexos de um currículo construído em contexto e no qual o uso da tecnologia foi elemento estruturante dessa construção. Os sujeitos apontam para aspectos como mudança na forma de ver o professor, percepção de que os erros também são importantes no processo de aprendizagem, mudança nas concepções prévias e percepção do movimento constante de rever-se em sua prática e como sujeito (a presença da práxis).

O segundo bloco, por sua vez, lança luz sobre um elemento essencial da aprendizagem compartilhada: a relação com a alteridade. A referência ao aprender com “outras” histórias e experiências respeitando as diferenças nos indica a existência de um trabalho de reconhecimento dos sujeitos envolvidos como sujeitos de conhecimentos; assim como a assunção dos papéis de professores e aprendizes por todos os membros do grupo. Ainda que esse fenômeno tenha se dado nas discussões feitas em sala de aula, o lócus de registro das histórias e aprendizagens individuais foi o blog - cuja leitura posterior levou a novas manifestações, questionamentos e aprendizagens.

A esse respeito, Arroyo (2013) defende a importância de reconhecer os saberes dos professores e revela que um dos conhecimentos não reconhecidos nos currículos de formação docente é aquele produzido na experiência cotidiana do professor - o que resulta no não reconhecimento deste como sujeito de conhecimento.

Entendemos que nossa experiência de utilização do blog na formação de professores em nível de mestrado possibilitou esse reconhecimento, bem como a ampliação do sentido atribuído pelos sujeitos envolvidos ao uso pedagógico da tecnologia.

Finalizamos este texto reiterando que as ferramentas digitais constituem-se valioso recurso para a formação de professores e podem instigar o uso pedagógico integrado das tecnologias no ensino de ciências - realidade ainda distante do atual contexto educacional brasileiro. Ainda assim, salientamos que, tanto na educação básica quanto na formação superior, não basta apenas romper o confinamento das salas de aula "mediante a irrupção das novas tecnologias. Falta, sem dúvida, o mais difícil: redefini-las como espaços de encontro e diálogo, de produção de pensamento e decantação de experiências capazes de insuflar consistência nas vidas que as habitam” (SIBILIA, 2012, p. 211). 


\section{Referências}

Almeida, M. E. B. \& Valente, J. A. (2011). Tecnologias e currículo: trajetórias convergentes ou divergentes?. São Paulo: Paulus.

Apple, M. W. (2006). Ideologia e currículo. Porto Alegre: Artmed.

Araujo, R. S; Vianna, D. M. (2011). A carência de professores de ciências e matemática na educação básica e a ampliação das vagas no ensino superior. Revista Ciência e Educação. (pp. 807-822) ,v.17, n.4.

Arroyo, M. G. (2013). Currículo: território em disputa. 5. ed. Petrópolis: Vozes.

Buzato, M.E.K. (2009). Letramentos Digitais, apropriação tecnológica e inovação. Anais III Encontro Nacional sobre Hipertexto (pp.1-12). Belo Horizonte:CEFET-MG.

https://www.ufpe.br/nehte/hipertexto2009/anais/g-l/let ramentos-digitais-apropriacao-tecnologica.pdf

Foucault, M. (1992). O que é um autor? 2. ed. São Paulo: Vega.

Gimeno Sacristán, J. (2013). Saberes e incertezas sobre o currículo. Porto Alegre: Penso.

Gimeno Sacristán, J. (2000). O currículo: uma reflexão sobre a prática. 3. ed. Porto Alegre: Artmed.

Komesu, F. C. (2010). Blogs e as práticas de escrita sobre si na internet. En L. A.Marcuschi; A. C. Xavier. (Ed.),
Hipertexto e géneros digitais: novas formas de construção de sentido (pp. 135-146). São Paulo: Cortez Editora.

Lage, M.C. (2011). Utilização do software NVivo em pesquisa qualitativa: uma experiência em EaD. Revista Educação Temática Digital (pp. 198-226). Campinas, v. 12, n. especial, mar/2011.

https://www.fe.unicamp.br/revistas/ged/etd/article/vie w/2313/pdf_57

Lévy, P. (1992). As tecnologias da inteligência: o futuro do pensamento na era informática. Lisboa: Instituto Piaget.

Lopes, A. C. \& Macedo, E. (2011). Teorias de currículo. São Paulo: Cortez.

Rodrigues, A. (2011). Escrita e autoria: entre histórias, memórias e descobertas. Campinas: Mercado de Letras.

Rojo, R. (2013). Gêneros discursivos do Círculo Bakhtin e multiletramentos. En R. Rojo (Ed.), Escol@ conectada: os multiletramentos e as TIC (pp. 13-36). São Paulo: Parábola.

Santaella, L., \& Nöth, W. (2012). Imagem: cognição, semiótica, mídia. São Paulo: Iluminuras.

Sibilia, P. (2012). Redes ou paredes: a escola em tempos de dispersão. Trad. Vera Ribeiro. Rio de Janeiro: Contraponto. 